COMENTARIO DE LIBROS

Rev Chil Salud Pública 2019, Vol 23(1): $85-86$
Carlos Madariaga A. Editor Asociado Revista Chilena de Salud Pública.

\section{SISTEMAS MÉDICOS EN LA ARAUCANÍA}

MEDICAL SYSTEMS IN THE ARAUCARIA REGION

YETHUAIMI THAMI THRIWE LAWEN..." (LLEVARÁS TU REMEDIO AMARGO)

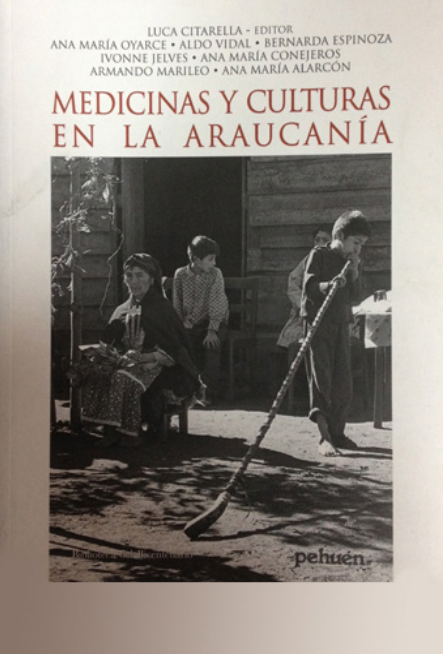

Tengo en mis manos una cuidadosa primera reedición de un texto publicado inicialmente el año 1995 por Editorial Sudamericana, que anuncia un diálogo cruzado entre culturas y sistemas médicos desde la región de la Araucanía: "Medicina y Cultura en la Araucanía" Editorial Pehuén 2019. Se trata de una incursión sobre las ciencias sociales y las ciencias de la salud con un material que, parapetado horizontalmente en la dialéctica ciencia/ política, incluye cuestiones como: la historia del pueblo mapuche; la relación de la cultura indígena con el tiempo histórico en que es escrito el texto (etapa final de la dictadura militar); la medicina tradicional mapuche y su relación con el sistema médico hegemónico y con otras formas de sanación popular; la cosmovisión mapuche; las relaciones de saber/poder con el Estado chileno en tanto pueblo/nación mapuche y en cuanto sistema de sanación; la concepción mapuche sobre la vida y la muerte, la salud y la enfermedad, sobre sus prácticas de sanación. Todos estos temas son abordados prolijamente en un texto extenso en el que abundan los datos complementarios y el trabajo de campo, la revisión bibliográfica, material fotográfico, estadísticas y gráficos. Se trata de una contundente producción teórica, en la que participa un grupo multidisciplinario de cientistas sociales y de la salud, que incluye la presencia de profesionales mapuche, todos ellos con presencia activa en el territorio de la Araucanía y que han sentido la necesidad de contar con un texto especializado que sistematice estas primeras experiencias de trabajo en salud desarrolladas por los autores junto al pueblo mapuche.

La pregunta es cuál sería el argumento que justifica esta reedición, dos y media décadas después. ¿Se trata de recuperar un texto histórico en tanto memoria científica de un conjunto de conocimientos que corresponden a una época pretérita o es la persistencia respecto de una temática sobre la cual se tiene la convicción de su actualidad, de su necesidad no solo historiográfica sino también epistemológica y praxiológica? Un dato ilustrativo para dilucidar esta cuestión es el hecho que a la época de la aparición de este texto, hace ya 25 años, recién empezaba en nuestro país a abrirse paso la idea de conocer por parte del Estado, en sus particularidades, la realidad del proceso salud - enfermedad de los pueblos indígenas de Chile. Una época en la que recién emergía en los años 90 el concepto de "interculturalidad" en la región latinoamericana, con la lucha de los movimientos indígenas aymara y quichua en Bolivia y Ecuador por el derecho a la tierra, por su reconocimiento como naciones, por su cultura y por la defensa de todas sus tradiciones, desde sus 
lenguas a sus prácticas médicas. El origen histórico de este concepto es, por tanto, estrictamente político y social pues responde, tanto en su génesis como en su desarrollo, a un proceso de ascenso de las demandas de los pueblos indígenas de la región, frente a injusticias e inequidades, principalmente de tipo étnicas, de clase y territoriales; un período de ascenso significativo del rol del movimiento indígena como actor social, al punto de producir importantes transformaciones políticas en ambos países, uno de cuyos logros más importantes fue la elaboración de constituciones políticas en las que hoy se reconocen muchos de sus derechos y se da estatus jurídico-constitucional a la interculturalidad.

El texto "Medicinas y Culturas en la Araucanía" surge en ese escenario social, cuando en Chile aún no se materializaba una política de salud pública con base en la interculturalidad. A nivel latinoamericano, y siguiendo el mandato del Consenso de Washington de los años 90, se despliega una estrategia internacional de etnogubernamentalidad y gobernanza destinado a encauzar el conflicto indígena regional, cautelando la estabilidad política que requiere la modernización neoliberal. Para estos efectos se apropió de categorías sociales y políticas de corte progresista en su retórica oficial, como participación social, diversidad cultural, derechos sociales, etc., pero con un toque de mistificación a lo Lampedussa ("Gatopardo") a objeto de configurar discursos de contención de las crisis sociales ligadas a las crecientes demandas indígenas de la región, de las cuales ha hecho parte históricamente el pueblo mapuche.

Es en ese momento cuando "interculturalidad" se transforma en un concepto polisémico, ambiguo, hasta errático, diferenciándose con claridad en la actualidad -siguiendo a C. Walsh- al menos dos corrientes asociadas a la interculturalidad: una, de carácter funcional-relacional que concibe el diálogo entre culturas como un escenario de intercambios mutuos, ajeno a las relaciones de hegemonía/ subalternidad en que se sustenta y, otra de carácter crítica, que reconoce los conflictos de poder, la lucha de intereses en juego y las demandas transformativas de las comunidades del subsuelo social. La primera está en la base de las políticas públicas de la mayoría de los países de la región formando parte de las estrategias de control social sobre las culturas subalternas; la segunda ha seguido el legado político que llevó a los pueblos aymara y quichua en Bolivia y Ecuador a protagonizar cambios sociales en favor de sus demandas históricas. La interculturalidad en salud es en Chile tributaria -en términos oficiales y en sus políticas y programas de salud dirigidos a los pueblos indígenas- de la forma funcional-relacional, aunque en los últimos años se abre camino en los espacios no hegemónicos una corriente crítica muy ligada a la salud colectiva y a los modelos de salud y salud mental comunitarios más avanzados. Podemos decir que la interculturalidad en salud es hoy un espacio de saberes y praxis en tensión y conflicto entre la etnogubernamentalidad y la producción de nuevas formas de subjetividad individual y social a partir de una concepción "otra" del proceso salud-enfermedad-atención, aquella que la define como un "hecho social total", en conceptos de E. Menéndez y A. Martínez $\mathrm{H}$.

El texto es un aporte al debate en curso, toda vez que vuelve a poner al servicio de la reflexión teórica un vasto conjunto de conocimientos asociados a la cultura mapuche, que conservan plena actualidad y proveen valiosos insumos no solo para nuestras preocupaciones teóricas sobre la interculturalidad en salud sino también - y diríamos, principalmentepara la praxis intercultural, uno de cuyos requisitos fundantes para su aplicación en el campo de la salud y la salud mental, especialmente para nuestros jóvenes equipos que configuran la red pública de salud, es la obligación de conocer con el máximo de rigurosidad posible las culturas subalternas, su historia, sus cosmovisiones, sus tradiciones, especialmente aquellas de tipo mágico-espirituales y de sanación, su concepción sobre la vida y la muerte, la salud y la enfermedad, su ideal comunitario, sus condiciones concretas de existencia (con A. Quijano diremos, sus condiciones de dominación y explotación y sus anhelos de reconocimiento y de redistribución), etc. De todos estos temas trata este libro; estimamos que los cambios sociales y políticos producidos en Chile en estos años desde su primera edición y los interesantes procesos abiertos en torno a la valiosa, aunque aún muy incipiente, apertura de las políticas públicas en salud hacia las tradiciones médicas de los pueblos indígenas son una incitación a lecturas y relecturas de sus contenidos. Aparte que siempre es un deleite, en nombre del fetichismo del libro, el tener entre manos un texto hermosamente editado y muy bien escrito. 